\title{
Do Protocadherins Show Prognostic Value in the Carcinogenesis of Human Malignant Neoplasms? Systematic Review and Meta-Analysis
}

\author{
Thaís Torres Barros Dutra ${ }^{1}$, Thâmara Manoela Marinho Bezerra ${ }^{1}$, Ealber \\ Carvalho Macêdo Luna ${ }^{1}$, Francisco Samuel Rodrigues Carvalho ${ }^{2}$, Filipe Nobre \\ Chaves $^{2}$, Paulo Goberlânio de Barros Silva ${ }^{1}$, Fábio Wildson Gurgel Costa ${ }^{1 *}$, \\ Karuza Maria Alves Pereira ${ }^{3}$
}

\begin{abstract}
Background: Protocadherins $(\mathrm{PCDHS})$ have been reported as tumor suppressor genes, implying that these genes may be involved in tumor suppression in a variety of cancers. However, a thorough understanding of the functions and mechanisms of $P C D H s$ remains limited. Our aim was to investigate the methylation profile of $P C D H s$ in human malignant neoplasms. Methods: This systematic review has been recorded in PROSPERO (\#42019117844) and conducted according to PRISMA's checklist; search was conducted in LILACS, PubMed, Science Direct, Scopus, and Web of Science databases, manually, with search queries and without date or language restrictions. Results: We found 91 articles, of which 26 were used for this meta-analysis and categorized according to the origin of the neoplasia. In total, 3,377 cases were compiled, with PCDH10, PCDH17, and PCDH8 being the most studied; males were 2.22 times more affected than females. Studies have shown significant heterogeneity $(\mathrm{p}<0.001)$, with the odds ratio varying between cases and controls $[2.20(95 \% \mathrm{CI}=1.11-4.35)$ to $209.05(95 \% \mathrm{CI}=12.64-2,457.18)]$, and the value of association between methylation and cancers studied was $26.08(95 \% \mathrm{CI}=15.42-44.13)$. Conclusion: In this systematic review, we have demonstrated using meta-analysis that PCDHs could emerge as potential tumor suppressor genes and that a significant increase in methylation may be useful for early detection of different cancers. This work may help in the identification of new prognostic biomarkers in malignant neoplasms.
\end{abstract}

Keywords: Cancer biomarkers- carcinogenesis- molecular biology

Asian Pac J Cancer Prev, 21 (12), 3677-3688

\section{Introduction}

Cadherin is a calcium-dependent adhesion protein that is a member of a large family of cell adhesion molecules. Cadherins can be classified into three groups: classical, desmosomal, and protocadherins ( $\mathrm{PCDHs}$ ). $\mathrm{PCDHs}$ are predominantly expressed in the nervous system and are primarily involved in the maintenance of brain functions. However, in recent years, it has been revealed in few studies that members of the $P C D H$ family may have other functions, including functions in some types of cancer (Narayan et al., 2009; Harada et al., 2015; Keeler et al., 2015; Shi et al., 2015; Deng et al., 2016; Lee et al., 2016; Ye et al., 2017).

$P C D H s$ are the largest subgroup of the cadherin superfamily and can be divided into two groups based on their genomic structure: clustered $P C D H s$, constituting gene clusters on a single chromosome, and ungrouped $P C D H s$, spread over different chromosomes (Wu et al., 2017; Zhong et al., 2017). Ungrouped human PCDH genes are often located at three chromo-somal loci: 4q28-31, 5q31-33, and 13q21 (Kim et al., 2011).

In contrast to classical cadherin, which establishes strong cell-cell adhesion through homo-philic interactions, $P C D H s$ have varied physiological functions, acting both as a mediator of cell-cell adhesion and as a regulator of other molecules (Yagi and Takeichi, 2000; Kim et al., 2011). In addition, according to a study, $P C D H s$ located on chromosome 13q21, such as $P C D H 8, P C D H 9, P C D H 17$, and $P C D H 20$, may be involved in tumor suppression (Kim et al., 2011). Recently, some $P C D H s$ have been reported as tumor suppressor genes, implying that these genes may

${ }^{1}$ Department of Clinical Dentistry, Faculty of Pharmacy and Dentistry and Nursing, Federal University of Ceara, Fortaleza, Brazil. ${ }^{2}$ School of Dentistry, Federal University of Ceara, Campus Sobral, Sobral, Brazil. ${ }^{3}$ Departament of Morphology, School of Medicine, Federal University of Ceará, Brazil. *For Correspondence: fwildson@yahoo.com.br 
be involved in tumor suppression in a variety of cancers (Imoto et al., 2006; Narayan et al., 2009; Yu et al., 2009; Hu et al., 2013; Wang et al., 2014; Keller et al., 2015; Shi et al., 2015; Deng et al., 2016; Lee et al., 2016; Ye et al., 2017; Zhong et al., 2017).

A detailed understanding of the functions and mechanisms of PCDHs remains limited, and, so far, there has been no systematic literature review in which the underlying mechanisms of $P C D H$ activity in carcinogenesis have been discussed. Thus, understanding the participation and actual role of $P C D H s$ in important cancer signaling pathways is fundamental for better elucidation of the regulatory and progressing intracellular mechanisms of carcinogenesis. Hence, our aim in this review was to investigate the expression of $P C D H S$ in primary malig-nant neoplasms.

\section{Materials and Methods}

This systematic review was conducted to summarize the current knowledge on $\mathrm{PCDH}$ expression in cancer, according to the Checklist of Preferred Reporting Items for Systematic Re-views and Meta-Analyses (PRISMA) (Additional file 1). The protocol has been registered in the International Prospective Register of Systematic Reviews (PROSPERO) database with the registration number CRD42019117844.

\section{Information sources and search strategy:}

The studies to be considered for inclusion were identified using a search strategy in each of the following electronic databases: LILACS, PubMed, Science Direct, Scopus, and Web of Science (Online Resource 1) (Additional file 2). A partial search for gray literature was per-formed using Google Scholar, OpenGrey, and ProQuest Dissertations and Theses Global. The gray database and bibliographic search included all articles published until October 21, 2019, without time restriction. Duplicate references were removed using the reference manager software (EndNote ${ }^{\circledR}$, Thomson Reuters). In addition, the reference lists of selected articles were manually selected for possible relevant studies that might have been missed during electronic database search.

\section{Eligibility Criteria}

Articles were selected without restrictions in year or language of publication; and the inclusion criteria adopted in this review were as follows: laboratory studies involving PCDH analysis in cancer and studies involving humans. The exclusion criteria were as follows: case reports, animal studies, literature reviews, and studies in which the clinical-pathological parameters were not presented.

\section{Study selection}

The selection of articles was performed in two phases. In phase 1, two reviewers independently (TTBD and EMCL) verified the titles and summaries of all of the identified electronic database citations. A third reviewer was involved as needed to make the final decision (KMAP). Studies that did not meet the inclusion criteria were omitted (Additional file 3). In phase 2, the same selection processes was carried out for full papers to confirm if the articles were suitable, according to inclusion criteria. TTBD and EMCL independently participated in phase 2 as well. The reference list of all of the included articles was reviewed by an examiner; however, both examiners read the selected articles. Any disagreement at any stage was resolved by discussion and mutual agreement.

\section{Data collection process}

One author (TTBD) collected important information from each article selected. A second reviewer (EMCL) cross-checked the information collected and confirmed its accuracy. Any disagreement between them was resolved by discussion and mutual agreement. For all studies included, the following information was recorded: author(s), year of publication, country, sex, age, smoking status, alcohol consumption pattern, HPV infection, sample size (study group and control group), tissue type (control and cancer), histological type, tumor differentiation, clinical staging, tumor size, tumor volume, lesion location, serum PSA (where applicable), disease progression, margin status, metastasis, biochemical recurrence (where applicable), follow-up time, death rate, survival, methodological design, and main results.

\section{Risk of bias in individual studies}

The risk of bias analysis of the studies was performed independently by two authors (TTBD and EMCL), in accordance to a questionnaire developed by the Joanna Briggs Institute (2017). The authors rated each item of the questionnaire as "yes", "no", "inaccurate", or "not applicable". The risk of bias was rated as high (up to $49 \%$ yes), moderate (50\% to $69 \%$ yes), and low (over $70 \%$ yes).

\section{Summary measures and synthesis of results}

The primary outcome for this systematic review was the use of $P C D H$ as a biomarker for cancer diagnosis. A secondary outcome would be the role of $P C D H$ as a tumor suppressor. Any type of measurement was considered in this review (categorical and continuous variables). Data were tabulated in an Excel ${ }^{\circledR}$ spreadsheet (Microsoft Corporation, Redmond, WA, USA) for relative and absolute frequencies and then exported to the Statistical Package for Social Sciences (version 17, IBM, Armonk, New York, USA) to perform statistical analysis. For meta-analysis, data were exported to MedCalc software for case-control meta-analysis. Der-Simonian Laird analyses were used to calculate the combined random effect odds ratios. A 95\% confidence interval was used for all evaluations. A total of 26 articles were included in the meta-analysis, which were also categorized according to the origin of the neoplasia (upper respiratory tract, gastrointestinal tract, and genitourinary tract).

\section{Results}

\section{Study selection}

At the end of phase 1, we could obtain 91 bibliographic references from the electronic database. However, 14 articles were present in more than one database (duplicate 
articles), after the removal of which, 77 articles remained for independent analysis by the reviewers. In addition, a manual search was conducted, and we found 25 additional articles from Google Scholar; however, we excluded 2 articles as these were duplicated. A flowchart of the study selection has been presented in Figure 1.

A full-text review was independently conducted by the reviewers, and 41 articles that met the inclusion criteria were selected. The studies that were excluded were as follows: laboratory studies involving $P C D H$ analysis in other pathologies; studies on blood, lymphatic, or brain malignant neoplasms; studies that did not use tumor samples for analysis; animal studies; and studies without clinical-pathological parameters described.

\section{Study characterization}

All of the studies included in this review were published in English language between the years 2006 and 2018 and were conducted in seven different countries, with most of the studies published in China $(n=34)$, followed by Japan $(n=3)$, Italy $(n=2)$, the Netherlands $(\mathrm{n}=1)$, and the Czech Republic $(\mathrm{n}=1)$. A summary of the descriptive characteristics of the included studies has been presented in Table 1.

In total, there were 6,645 cases on malignant neoplasm
Prognostic Value the Protocadherins in Carcinogenesis

in the forty-one studies that were selected as sample, and the number of cases in the sample ranged between 2816 and 107,217 . The total number of controls were 1,934, and 7 studies reported no control group (Losi et al., 2011; Chen et al., 2015; Harada et al., 2015; Hou et al., 2015; Lv et al., 2015; Wu et al., 2017; Cao et al., 2018).

Most of the studies reported genitourinary tract $(\mathrm{n}=$ $19 ; 46.34 \%)$ or gastrointestinal tract $(n=15 ; 36.59 \%)$ neoplasms. From the studies in which the patient's gender was reported, we observed that $74.43 \%(5,087 / 6,835)$ of the patients were male and $25,57 \%(1,748 / 6,835)$ were female, with the average male:female ratio being 2.91 . The most-studied $\mathrm{PCDHs}$ were $\mathrm{PCDH10}, \mathrm{PCDH} 8$, and PCDH17 (Figure 2).

Immunoexpression of PCDHs in malignant neoplasms is negative or low, and methylation is a specific tumor event

The immunohistochemical profile was evaluated in 13 articles in which negative or low immunoexpression was reported (Haruki et al., 2010; Losi et al., 2011; Ma et al., 2013; Chen et al., 2015; Chen et al., 2015; Harada et al., 2015; Dang et al., 2016; Lin et al., 2016; Zhang et al., 2016; Chen et al., 2017; Wu et al., 2017; Cao et al., 2018; Li et al., 2018). The methylation profile of PCDHs in malignant neoplasms was evaluated in 33 studies

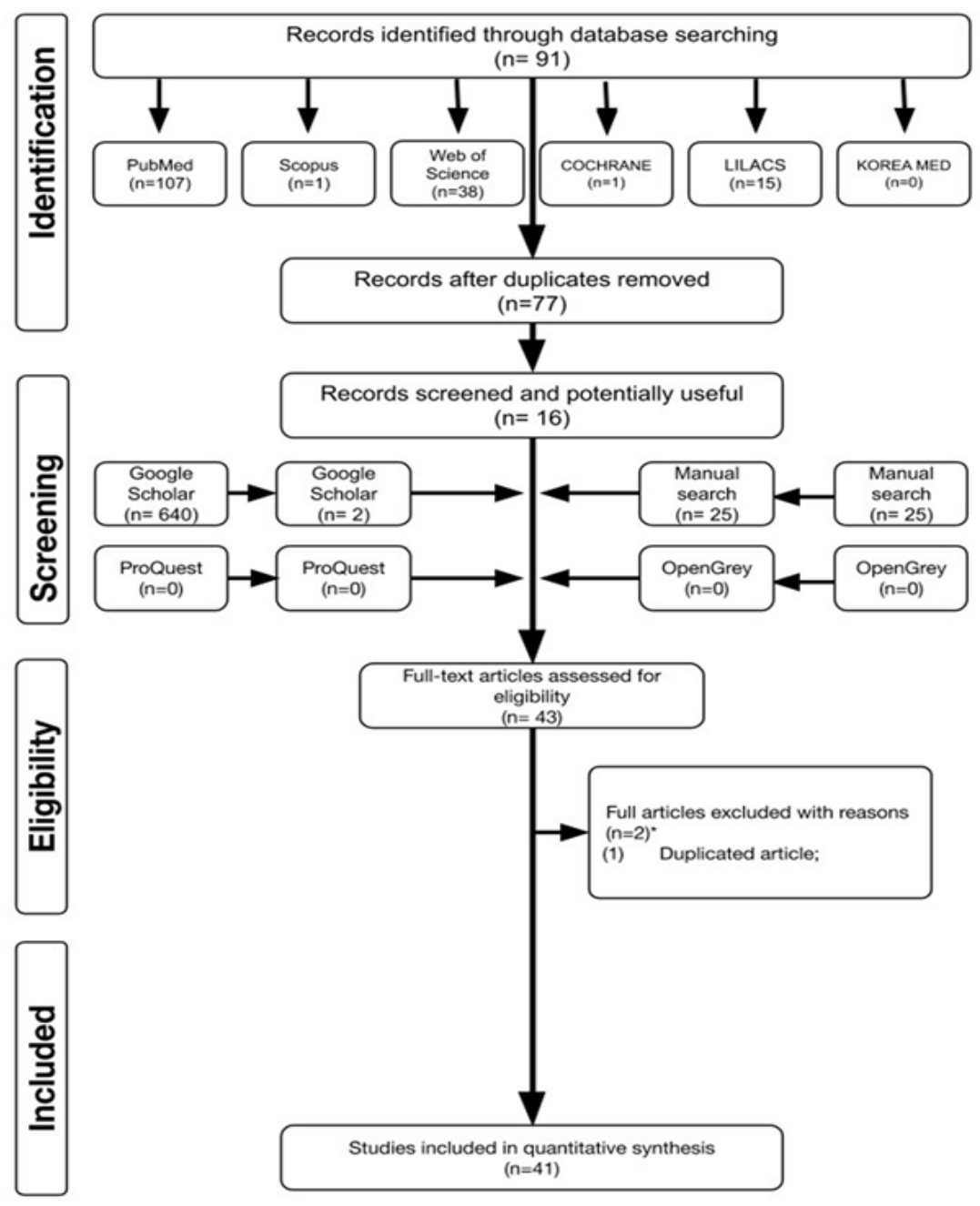

Figure 1. Flow Diagram of PRISMA's Adapted Literature Search and Selection Criteria. 


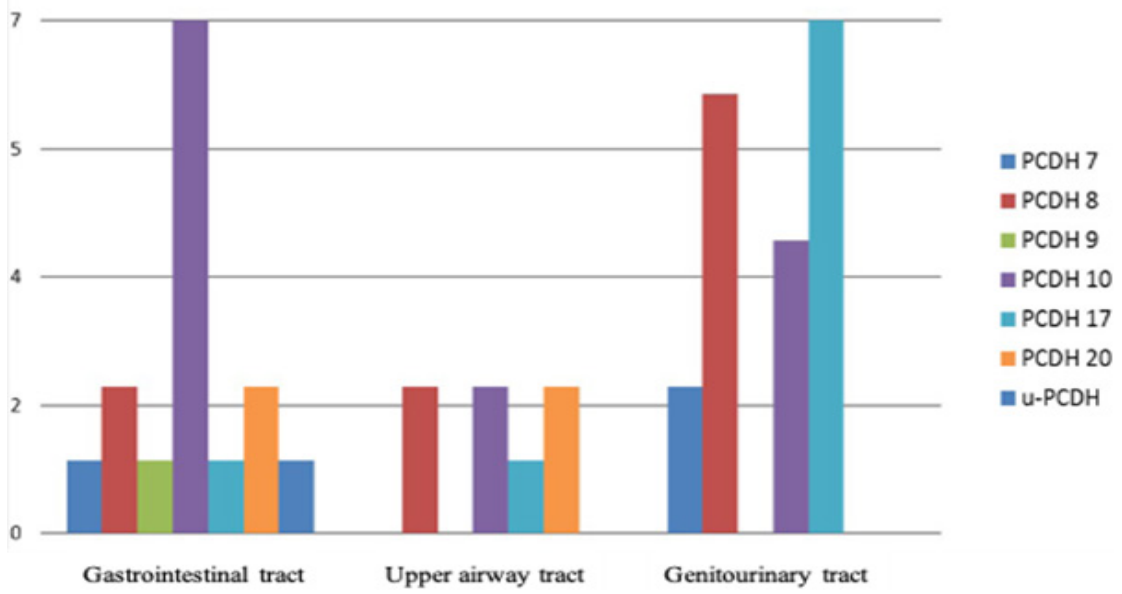

Figure 2. Distribution of the Types of PCDHs Studies among the Categories of Neoplasms $(n=41)$.

(Imoto et al., 2006; Yu et al., 2009; Haruki et al., 2010; Yu et al., 2010; He et al., 2012; Zhang et al., 2012; Lin et al., 2012; Beukers et al., 2013; Danese et al., 2013; Fang et al., 2013; Lin et al., 2013; Tang et al., 2013; Deng et al 2014; Wang et al., 2014; Lin et al., 2014; Lin et al., 2014; Lin et al., 2014; Luo et al., 2014; Niu et al., 2014; Wang et al., 2014; Chen et al., 2015; Chen et al., 2015; Harada et al., 2015; Hou et al., 2015; Lin et al., 2015; Lin et al., 2015; Lv et al., 2015; Deng et al., 2016; Lin et al., 2016; Zhang et al., 2016; Lin et al., 2017; Lin et al., 2017; Baranova et al., 2018; Li et al., 2018), and in 7 studies (Imoto et al., 2006; Beukers et al., 2013; Chen et al., 2015; Harada et al., 2015; Hou et al., 2015; Lv et al., 2015; Lin et al., 2016) the values for controls were not reported. Overall, methylation occurred more frequently in the cases than in the controls.

Malignant neoplasms show significant increase in methylation

In total, 26 articles were included in this metaanalysis, which were also categorized according to the origin of neoplasia, and 3,377 cases and 1,638 controls were compiled. In the studies, we observed that there was significant heterogeneity $(\mathrm{p}<0.001)$, with a fairly variable odds ratio between cases and controls [2.20 (95\% $\mathrm{CI}=1.11 .4 .35)$ to $209.05(95 \% \mathrm{CI}=12.64 .2 .457 .18)]$, and the value of association between methylation and the cancers studied was found to be 26.08 (95\% CI 15.42. 44.13) (Figure 3). Depending on the site of origin of neoplasm, the tumors of the upper respiratory

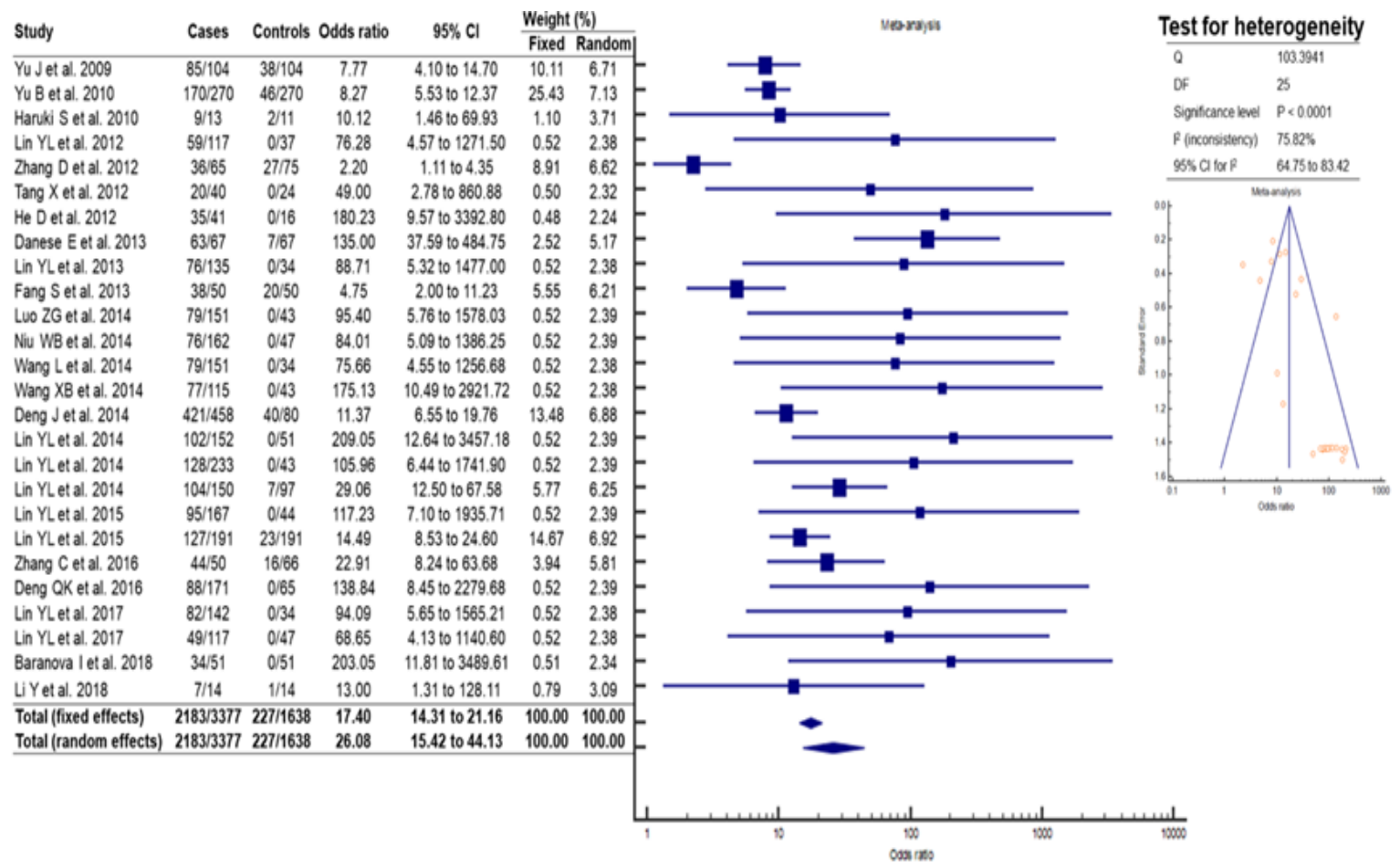

Figure 3. Methylation Profile in Human Malignant Neoplasms $(\mathrm{n}=26)$ 
Table 1. Summary of Descriptive Characteristics of the Included Studies $(n=41)$

\begin{tabular}{|c|c|c|c|c|c|c|c|}
\hline $\begin{array}{l}\text { Author } \\
\text { (year), } \\
\text { Country }\end{array}$ & $\begin{array}{l}\text { Localization } \\
\text { of Malignant } \\
\text { Neoplasia }\end{array}$ & $\begin{array}{l}\mathrm{N} \\
\text { Case }\end{array}$ & $\begin{array}{l}\mathrm{N} \\
\text { Controls }\end{array}$ & Gender & $\mathrm{PCDH}$ & Method Analyse & Conclusions \\
\hline $\begin{array}{l}\text { Baranova et } \\
\text { al. (2018), } \\
\text { Czech } \\
\text { Republic }\end{array}$ & Ovary & 51 & 35 & NI & PCDH17 & Methylation & $\begin{array}{l}\text { PCDH17 methylation was detected in almost } 70 \% \\
\text { of group case and gene expression analysis revealed } \\
\text { decreased expression in all of the tumor samples in } \\
\text { comparison to the control ones. Statistically significant } \\
\text { negative correlation was found between methylation and } \\
\text { levels of expression suggesting potentially methylation- } \\
\text { based silencing. }\end{array}$ \\
\hline $\begin{array}{l}\text { Bing et } \\
\text { al. }(2018) \text {, } \\
\text { China }\end{array}$ & Hepatic & 109 & 109 & $\begin{array}{l}\text { F: } 51 \\
\text { M: } 58\end{array}$ & PCDH10 & Gene expression & $\begin{array}{l}\text { PCDH10 expression was lower in tumor tissues than } \\
\text { that in adjacent nontumor tissues. Kaplan-Meier curves } \\
\text { showed that patients with lower PCDH10 expression } \\
\text { had a worse overall survival. Moreover, PCDH10 } \\
\text { expression level was associated tumor size, tumor node } \\
\text { metastasis stage, smoking status and drinking status. }\end{array}$ \\
\hline $\begin{array}{l}\text { Cao et al. } \\
(2018) \text {, } \\
\text { China }\end{array}$ & Ovary & 68 & 0 & NI & PCDH8 & $\begin{array}{l}\text { Immunohistochemistry } \\
\text { and others }\end{array}$ & $\begin{array}{l}\text { Protocaderin- } 8 \text { can be considered as a tumor suppressor } \\
\text { and play a crucial role in the progression of ovarian } \\
\text { cancer. }\end{array}$ \\
\hline $\begin{array}{l}\text { Li et al. } \\
(2018) \\
\text { China }\end{array}$ & Hypopharynx & 80 & 80 & $\begin{array}{l}\text { F: } 2 \\
\text { M: } 78\end{array}$ & PCDH8 & $\begin{array}{l}\text { Immunohistochemistry, } \\
\text { Methylation and others }\end{array}$ & $\begin{array}{l}\text { PCDH8 may serve as a useful prognostic biomarker } \\
\text { and potential therapeutic target for patients with } \\
\text { hypopharyngeal carcinoma. }\end{array}$ \\
\hline $\begin{array}{l}\text { Chen et } \\
\text { al. (2017), } \\
\text { China }\end{array}$ & Gastric & 119 & 75 & $\begin{array}{l}\mathrm{F}^{*}: 21 \\
(17.6 \%) \\
\mathrm{M}^{*}: 98 \\
(82.4 \%)\end{array}$ & PCDH7 & $\begin{array}{l}\text { Immunohistochemistry } \\
\text { and others }\end{array}$ & $\begin{array}{l}\text { Low expression and decreased PCDH7 may promote } \\
\text { cell migration and invasion by inhibiting E-cadherin } \\
\text { expression. }\end{array}$ \\
\hline $\begin{array}{l}\text { Lin et al. } \\
(2017) \text {, } \\
\text { China }\end{array}$ & Prostate & 117 & 47 & M: 117 & PCDH8 & Methylation & $\begin{array}{l}\text { PCDH8 was methylated in serum samples of case } \\
\text { than in controls. This methylation was correlated with } \\
\text { advanced clinical stage, higher level of preoperative } \\
\text { PSA, and positive lymph node metastasis. Moreover, } \\
\text { patients with PCDH8 methylation had worse BCR-free } \\
\text { survival than patients without. }\end{array}$ \\
\hline $\begin{array}{l}\text { Lin et al. } \\
(2017) \text {, } \\
\text { China }\end{array}$ & Kidney & 142 & 34 & $\begin{array}{l}\text { F: } 45 \\
\text { M: } 97\end{array}$ & PCDH17 & Methylation & $\begin{array}{l}\text { PCDH17 was more methylated in case than in controls } \\
\text { and methylation in serum was correlated with advanced } \\
\text { stage, higher grade, lymph node metastasis and tumor } \\
\text { progression. In addition, patients with methylated } \\
\text { PCDH17 had shorter progression-free survival and } \\
\text { overall survival than patients without, and methylation } \\
\text { in serum was an independent prognostic factor for } \\
\text { worse progression-free survival and overall survival of } \\
\text { patients. }\end{array}$ \\
\hline $\begin{array}{l}\text { Wu et al. } \\
(2017) \\
\text { China. }\end{array}$ & Hepatic & 317 & 0 & $\begin{array}{l}\text { F: } 35 \\
(11 \%) \\
\text { M: } 282 \\
(89 \%)\end{array}$ & PCDH20 & Immunohistochemistry & $\begin{array}{l}\text { Decreased expression of protocadherin } 20 \text { was observed } \\
\text { in patients and was an independent risk factor for } \\
\text { mortality. }\end{array}$ \\
\hline $\begin{array}{l}\text { Deng et } \\
\text { al. }(2016) \text {, } \\
\text { China }\end{array}$ & Prostate & 171 & 65 & $\begin{array}{l}M^{*}: \\
236\end{array}$ & PCDH10 & Methylation & $\begin{array}{l}\text { PCDH10 methylation was significantly associated with } \\
\text { higher preoperative PSA level, advanced clinical stage, } \\
\text { higher Gleason score, lymph node metastasis and BCR. } \\
\text { In addition, patients with methylated PCDH10 had } \\
\text { shorter BCR-free survival and overall survival. The } \\
\text { methylation in serum is an independent predictor of } \\
\text { worse BCR-free survival and overall survival. }\end{array}$ \\
\hline $\begin{array}{l}\text { Lin et al. } \\
(2016) \\
\text { China }\end{array}$ & $\begin{array}{l}\text { Bladder (non } \\
\text { invasive } \\
\text { muscle) }\end{array}$ & 199 & 25 & $\begin{array}{l}\text { F: } 61 \\
(30.7 \%) \\
\text { M: } 138 \\
(69.3 \%)\end{array}$ & $\mathrm{PCDH} 7$ & Immunohistochemistry & $\begin{array}{l}\text { PCDH7 expression was decreased in invasive non- } \\
\text { muscular bladder cancer tissues and low PCDH7 } \\
\text { expression was associated with high pathological } \\
\text { grade, relapse, and tumor progression. In addition, } \\
\text { low expression is an independent prognostic factor for } \\
\text { patient outcome. }\end{array}$ \\
\hline $\begin{array}{l}\text { Zhang et } \\
\text { al. (2016), } \\
\text { China }\end{array}$ & Hepatic & 50 & 50 & $\begin{array}{l}\mathrm{F}^{*}: 39 \\
\mathrm{M}^{*}: 11\end{array}$ & PCDH8 & $\begin{array}{l}\text { Immunohistochemistry } \\
\text { and Methylation }\end{array}$ & $\begin{array}{l}\text { PCDH8 is often inactivated by promoter methylation } \\
\text { in liver cancer and can serve as a valuable diagnostic } \\
\text { biomarker for early detection and for predicting an } \\
\text { unfavorable clinical feature. }\end{array}$ \\
\hline $\begin{array}{l}\text { Chen et } \\
\text { al. (2015), } \\
\text { China }\end{array}$ & Nasopharyngeal & 51 & 13 & $\begin{array}{l}\mathrm{F}^{*}: 12 \\
\mathrm{M}^{*}: 39\end{array}$ & PCDH20 & $\begin{array}{l}\text { Immunohistochemistry, } \\
\text { Methylation and others }\end{array}$ & $\begin{array}{l}\text { PCDH } 20 \text { can inhibit cell proliferation, migration and } \\
\text { invasion by antagonizing the Wnt/ } \beta \text {-catenin and EMT } \\
\text { signaling pathway in nasopharyngeal cancer. }\end{array}$ \\
\hline $\begin{array}{l}\text { Chen et } \\
\text { al. (2015), } \\
\text { China }\end{array}$ & Gastric & $\begin{array}{l}1 \\
072\end{array}$ & 0 & $\begin{array}{l}\text { F: } 315 \\
(29.4 \%) \\
\text { M: } 757 \\
(70.6 \%)\end{array}$ & PCDH9 & $\begin{array}{l}\text { Immunohistochemistry, } \\
\text { Methylation and others }\end{array}$ & $\begin{array}{l}\text { Decreased expression of } \mathrm{PCDH} 9 \text { is frequent in } \\
\text { metastases of human gastric cancer and its expression is } \\
\text { an independent prognostic factor. }\end{array}$ \\
\hline $\begin{array}{l}\text { Dang et } \\
\text { al. }(2015) \text {, } \\
\text { China }\end{array}$ & Hepatic & 86 & 78 & $\begin{array}{l}\text { F: } 22 \\
\text { M: } 64\end{array}$ & PCDH17 & $\begin{array}{l}\text { Immunohistochemistry } \\
\text { and others }\end{array}$ & $\begin{array}{l}\text { PCDH-17 expression was clinically correlated with } \\
\text { overall prognosis as well as metas- tasis in vivo and } \\
\text { inhibit metastasis via EGFR/MEK/ERK signaling } \\
\text { pathway ex vivo. }\end{array}$ \\
\hline $\begin{array}{l}\text { Harada et } \\
\text { al. }(2015) \text {, } \\
\text { China }\end{array}$ & $\begin{array}{l}\text { Lung (non-small } \\
\text { cells) }\end{array}$ & 109 & 0 & $\begin{array}{l}\text { F: } 42 \\
\text { M: } 67\end{array}$ & PCDH10 & $\begin{array}{l}\text { Immunohistochemistry } \\
\text { and Methylation }\end{array}$ & $\begin{array}{l}\text { PCDH10 promoter methylation plays a significant role } \\
\text { in the progression of non-small cell lung cancer and } \\
\text { may be a promising prognostic marker for patients with } \\
\text { curatively resected pathological stage I. }\end{array}$ \\
\hline
\end{tabular}


Table 1. Continued

\begin{tabular}{|c|c|c|c|c|c|c|c|}
\hline $\begin{array}{l}\text { Author } \\
\text { (year), } \\
\text { Country }\end{array}$ & $\begin{array}{l}\text { Localization } \\
\text { of Malignant } \\
\text { Neoplasia }\end{array}$ & $\begin{array}{l}\mathrm{N} \\
\text { Case }\end{array}$ & $\begin{array}{l}\mathrm{N} \\
\text { Controls }\end{array}$ & Gender & $\mathrm{PCDH}$ & Method Analyse & Conclusions \\
\hline $\begin{array}{l}\text { Hou et al. } \\
(2015) \text {, } \\
\text { Japan }\end{array}$ & Gastric & 471 & 0 & $\begin{array}{l}\text { F: } 118 \\
(25.1 \%) \\
\text { M: } 353 \\
(74.9 \%)\end{array}$ & PCDH10 & Methylation & $\begin{array}{l}\text { Current findings suggest that the count of hypermethylated } \mathrm{CpG} \\
\text { sites from the PCDH10 DNA promoter to assess the prognosis } \\
\text { of gastric cancer.s }\end{array}$ \\
\hline $\begin{array}{l}\text { Lin et al. } \\
(2015) \\
\text { China }\end{array}$ & Prostate & 167 & 44 & M: 211 & PCDH17 & Methylation & $\begin{array}{l}\text { PCDH17 methylation was associated with advanced } \\
\text { pathological stage, higher Gleason score, high- er preoperative } \\
\text { PSA levels, BCR, and shorter BCR-free survival. }\end{array}$ \\
\hline $\begin{array}{l}\text { Lin et al. } \\
(2015) \\
\text { China }\end{array}$ & Kidney & 191 & 191 & $\begin{array}{l}F^{*}: 77 \\
(40.3 \%) \\
M^{*}: 114 \\
(59.7 \%)\end{array}$ & PCDH17 & Methylation & $\begin{array}{l}\text { PCDH17 methylation is significantly correlated with advanced } \\
\text { stage, higher grade, and lymph node metastasis. Moreover, it is } \\
\text { an independent prognostic factor for progression-free survival } \\
\text { and overall survival of patients. }\end{array}$ \\
\hline $\begin{array}{l}\text { Lv et al. } \\
(2015) \\
\text { China }\end{array}$ & Hepatic & 107 & 0 & $\begin{array}{l}\text { F: } 35 \mathrm{M}: \\
72\end{array}$ & PCDH20 & $\begin{array}{l}\text { Methylation and } \\
\text { others }\end{array}$ & $\begin{array}{l}\mathrm{PCDH} 20 \text { can inhibit cell proliferation and cell migration, } \\
\text { through antagonizing Wnt/b-catenin signalling pathway }\end{array}$ \\
\hline $\begin{array}{l}\text { Deng et } \\
\text { al. }(2014) \text {, } \\
\text { China }\end{array}$ & Gastric & 458 & 25 & $\begin{array}{l}\mathrm{F}^{*}: 145 \\
(31.6 \%) \\
\mathrm{M}^{*}: 313 \\
(68.34 \%)\end{array}$ & PCDH10 & $\begin{array}{l}\text { Methylation and } \\
\text { others }\end{array}$ & $\begin{array}{l}\text { Protocadherin- } 10 \text { promoter methylation was more in case and } \\
\text { was associated with poorer survival. }\end{array}$ \\
\hline $\begin{array}{l}\text { Lin et al. } \\
(2014) \\
\text { China }\end{array}$ & Prostate & 152 & 51 & M: 203 & PCDH17 & Methylation & $\begin{array}{l}\text { PCDH17 methylation occurred in prostate cancer and was } \\
\text { associated with higher pathological Gleason score, advanced } \\
\text { pathological stage, higher level of preoperative PSA, positive } \\
\text { angiolymphatic invasion, positive lymph node metastasis, and } \\
\text { BCR. In addition, methylation was an independent predictor of } \\
\text { poor BCR-free survival and overall survival for patients with } \\
\text { prostate cancer. }\end{array}$ \\
\hline $\begin{array}{l}\text { Lin et al. } \\
(2014) \text {, } \\
\text { China }\end{array}$ & Kidney & 153 & 97 & $\begin{array}{l}F^{*}: 51 \\
(33.3 \%) \\
M^{*}: 102 \\
(66.7 \%)\end{array}$ & PCDH8 & Methylation & $\begin{array}{l}\text { PCDH8 methylation was more frequent in tumor tissues and } \\
\text { was significantly correlated with advanced clinical stage, higher } \\
\text { grade, and lymph node metastasis. In addition, methylation was } \\
\text { independently associated with poor progression-free survival. }\end{array}$ \\
\hline $\begin{array}{l}\text { Lin et al. } \\
(2014) \text {, } \\
\text { China }\end{array}$ & $\begin{array}{l}\text { Bladder (non } \\
\text { invasive } \\
\text { muscle) }\end{array}$ & 233 & 43 & $\begin{array}{l}F^{*}: 72 \\
M^{*}: 161\end{array}$ & PCDH8 & Methylation & $\begin{array}{l}\text { PCDH8 methylation occurred in tumor tissues and was } \\
\text { correlated with advanced stage, high grade, larger tumor size, } \\
\text { tumor recurrence and progression. The patients with PCDH8 } \\
\text { methylated have shorter recurrence-free survival, progression- } \\
\text { free survival and five-year overall survival. }\end{array}$ \\
\hline $\begin{array}{l}\text { Luo et al. } \\
(2014) \text {, } \\
\text { China }\end{array}$ & Bladder & 151 & 43 & $\begin{array}{l}\mathrm{F}: 56 \mathrm{M}: \\
138\end{array}$ & PCDH17 & Methylation & $\begin{array}{l}\text { PCDH17 promoter methylation was detected in } 52.3 \% \text { of } \\
\text { patients with bladder cancer and was associated with larger } \\
\text { tumour diameter, high grade and advanced stage. Patients with } \\
\text { PCDH17 promoter methylation had significantly shorter overall } \\
\text { survival than those with unmethylated PCDH17 promoter. }\end{array}$ \\
\hline $\begin{array}{l}\text { Niu et al. } \\
(2014) \text {, } \\
\text { China }\end{array}$ & Prostate & 162 & 47 & M: 209 & PCDH8 & Methylation & $\begin{array}{l}\text { PCDH8 methylation occurred in tumor tissues and was } \\
\text { associated with advanced pathologic stage, higher level of } \\
\text { preoperative PSA, higher Gleason score, positive lymph node } \\
\text { metastasis, and biochemical recurrence. The patients with } \\
\text { methylated have shorter BCR-free survival time. }\end{array}$ \\
\hline $\begin{array}{l}\text { Wang et } \\
\text { al. (2014), } \\
\text { China }\end{array}$ & Prostate & 151 & 34 & M: 185 & PCDH10 & Methylation & $\begin{array}{l}\text { PCDH10 methylation was more in tumor tissue and was } \\
\text { associated with higher preoperative PSA level, higher Gleason } \\
\text { Score, advanced clinical stage, lymph node metastasis, } \\
\text { angiolymphatic invasion, biochemical recurrence and may be } \\
\text { used as an independent predictor of BCR-free survival. }\end{array}$ \\
\hline $\begin{array}{l}\text { Wang et } \\
\text { al. (2014), } \\
\text { China }\end{array}$ & Bladder & 115 & 43 & $\begin{array}{l}\text { F: } 45 \mathrm{M}: \\
113\end{array}$ & PCDH17 & Methylation & $\begin{array}{l}\text { Methylation of the PCDH17 promoter was detected in tumor } \\
\text { tissueand was associated with high cancer grade, advanced } \\
\text { cancer stage, large tumour diameter and tumour recurrence. } \\
\text { Methylation was also associated with significantly shorter } \\
\text { survival time. }\end{array}$ \\
\hline $\begin{array}{l}\text { Beukers et } \\
\text { al. (2013), } \\
\text { Netherlands }\end{array}$ & Bladder & 167 & 35 & $\begin{array}{l}\mathrm{F}^{*}: 36 \\
(22 \%) \\
\mathrm{M}^{*}: 131 \\
(78 \%)\end{array}$ & PCDH7 & Methylation & $\begin{array}{l}\text { PCDH7 showed high methylation ratios in all age categories } \\
\text { and could therefore play an important role in early urothelial } \\
\text { carcinogenesis. }\end{array}$ \\
\hline $\begin{array}{l}\text { Danese et } \\
\text { al. }(2013) \text {, } \\
\text { Italy }\end{array}$ & Colorectal & 67 & $67 * *$ & $\begin{array}{l}\text { F: } 22 \\
(34.9 \%) \\
\text { M: } 41 \\
(65.1 \%)\end{array}$ & PCDH10 & Methylation & $\begin{array}{l}\text { PCDH10 methylation detected in plasma increased with } \\
\text { increasing methylation rate in tumor tissues only in early stage } \\
\text { cancers, while this correlation was apparently lost in advanced } \\
\text { stages. }\end{array}$ \\
\hline $\begin{array}{l}\text { Fang et } \\
\text { al. }(2013) \text {, } \\
\text { China }\end{array}$ & Hepatic & 50 & $50 * *$ & $\begin{array}{l}\text { F: } 16 \mathrm{M}: \\
34\end{array}$ & PCDH10 & $\begin{array}{l}\text { Methylation and } \\
\text { others }\end{array}$ & $\begin{array}{l}\text { PCDH10 methylation was detected in tumor tissues compared. } \\
\text { There were correlations between methylation status of and } \\
\text { tumor size, serum AFP levels, metastasis or TNM staging. }\end{array}$ \\
\hline $\begin{array}{l}\text { Lin et al. } \\
(2013) \\
\text { China }\end{array}$ & Bladder & 135 & 34 & $\begin{array}{l}\mathrm{F}: 49 \mathrm{M}: \\
120\end{array}$ & PCDH8 & Methylation & $\begin{array}{l}\text { PCDH8 promoter methylation was detected in tumor } \\
\text { tissue and was associated with advanced stage, high grade, } \\
\text { tumour recurrence, larger tumour diameter and nonpapillary } \\
\text { morphology. In addition, methylation was associated with } \\
\text { significantly shorter survival time and was an independent } \\
\text { predictor of overall survival. }\end{array}$ \\
\hline
\end{tabular}


Table 1. Continued

\begin{tabular}{|c|c|c|c|c|c|c|c|}
\hline $\begin{array}{l}\text { Author } \\
\text { (year), } \\
\text { Country }\end{array}$ & $\begin{array}{l}\text { Localization } \\
\text { of Malignant } \\
\text { Neoplasia }\end{array}$ & $\begin{array}{l}\mathrm{N} \\
\text { Case }\end{array}$ & $\begin{array}{l}\mathrm{N} \\
\text { Controls }\end{array}$ & Gender & $\mathrm{PCDH}$ & Method Analyse & Conclusions \\
\hline $\begin{array}{l}\text { Ma et al. } \\
(2013) \\
\text { China }\end{array}$ & Bladder & 105 & 33 & $\begin{array}{l}\text { F: } 38 \\
\text { M: } 100\end{array}$ & PCDH10 & Immunohistochemistry & $\begin{array}{l}\text { Downregulated PCDH10 levels correlated with } \\
\text { malignant behaviour and poor overall survival in } \\
\text { patients with bladder cancer. Downregulated }\end{array}$ \\
\hline $\begin{array}{l}\text { He et al. } \\
(2012) \\
\text { China }\end{array}$ & Nasopharyngeal & 41 & 16 & $\begin{array}{l}\text { F: } 10 \\
\text { M: } 31\end{array}$ & PCDH8 & Methylation and others & $\begin{array}{l}\text { Ectopic expression of PCDH8 in silenced NPC cells } \\
\text { significantly inhibited cell colony formation and cell } \\
\text { migration. Thus, PCDH8 could be identified as a } \\
\text { tumor suppressor in this cancer. }\end{array}$ \\
\hline $\begin{array}{l}\text { Lin et al. } \\
(2012) \\
\text { China }\end{array}$ & Bladder & 117 & 37 & $\begin{array}{l}\text { F: } 50 \\
\text { M: } 104\end{array}$ & PCDH10 & Methylation & $\begin{array}{l}\text { PCDH10 promoter methylation was detected in tumor } \\
\text { tissue and was associated with advanced stage, high } \\
\text { grade, tumour recurrence and larger tumour size. In } \\
\text { addition, methylation was associated with significantly } \\
\text { worse survival and was an independent predictor of } \\
\text { overall survival. }\end{array}$ \\
\hline $\begin{array}{l}\text { Tang et } \\
\text { al. }(2012) \text {, } \\
\text { China }\end{array}$ & Lung & 40 & 24 & $\begin{array}{l}\mathrm{F}^{*}: 12 \\
\mathrm{M}^{*}: 28\end{array}$ & PCDH10 & Methylation and others & $\begin{array}{l}\text { PCDH10 was downregulated in tumor tissues and } \\
\text { methylation of was observed \% tumor tissues but } \\
\text { not in tumor-adjacent or normal tissues. Ectopic } \\
\text { expression of PCDH10 in silenced cells can reduce } \\
\text { lung cancer cell proliferation and migration. }\end{array}$ \\
\hline $\begin{array}{l}\text { Zhang et } \\
\text { al. (2012), } \\
\text { China }\end{array}$ & Gastric & 65 & 10 & $\begin{array}{l}F^{*}: 23 \\
M^{*}: 42\end{array}$ & PCDH8 & Methylation and others & $\begin{array}{l}\text { PCDH } 8 \text { methylation was observed in alls cell lines } \\
\text { and } 55.38 \% \text { of the primary tumor, but not in normal } \\
\text { gastric mucosa, and was associated with lymph node } \\
\text { metastasis. }\end{array}$ \\
\hline $\begin{array}{l}\text { Losi et } \\
\text { al. }(2011) \\
\text { Italy }\end{array}$ & Colorectal & 28 & 0 & $\begin{array}{l}\text { F: } 13 \\
\text { M: } 15\end{array}$ & $\mathrm{u}-\mathrm{PCDH}$ & $\begin{array}{l}\text { Immunohistochemistry } \\
\text { and others }\end{array}$ & $\begin{array}{l}\text { Down regulation of } \mu \text {-protocadherin expression is a } \\
\text { common event in colorectal carcinogenesis and may } \\
\text { therefore play an important role in this pathological } \\
\text { process. }\end{array}$ \\
\hline $\begin{array}{l}\text { Haruki et } \\
\text { al. (2010), } \\
\text { Japan }\end{array}$ & Esophageal & 145 & $13 * *$ & $\begin{array}{l}\mathrm{F}^{*}: 16 \\
\mathrm{M}^{*}: 129\end{array}$ & PCDH17 & $\begin{array}{l}\text { Immunohistochemistry, } \\
\text { Methylation and others }\end{array}$ & $\begin{array}{l}\text { Silencing of PCDH17 expression through } \\
\text { hypermethylation of the promoter or other } \\
\text { mechanisms leads to loss of its tumour-suppressive } \\
\text { activity. }\end{array}$ \\
\hline $\begin{array}{l}\text { Yu et al. } \\
(2010) \\
\text { China }\end{array}$ & $\begin{array}{l}\text { Gastric, } \\
\text { Colorectal, } \\
\text { Pancreatic }\end{array}$ & 270 & $270 * *$ & NI & PCDH10 & Methylation & $\begin{array}{l}\text { PCDH10 methylation was higher in precancerous } \\
\text { lesions than in chronic gastritis samples and } \\
\text { Kaplan-Meier survival curves showed that PCDH10 } \\
\text { methylation was associated signif- icantly with } \\
\text { shortened survival in stage I-III gastric cancer } \\
\text { patients. }\end{array}$ \\
\hline $\begin{array}{l}\text { Yu et al. } \\
(2009) \\
\text { China }\end{array}$ & Gastric & 104 & $104 * *$ & $\begin{array}{l}\mathrm{F}^{*}: 45 \\
\mathrm{M}^{*}: 57\end{array}$ & PCDH10 & Methylation and others & $\begin{array}{l}\text { A PCDH10 é um supressor de tumor gástrico; sua } \\
\text { metilação nas fases iniciais da carcinogênese gástrica é } \\
\text { um fator prognóstico independente. }\end{array}$ \\
\hline $\begin{array}{l}\text { Imoto et } \\
\text { al. }(2006) \text {, } \\
\text { Japan }\end{array}$ & $\begin{array}{l}\text { Lung (non- } \\
\text { small cells) }\end{array}$ & 59 & 12 & $\begin{array}{l}\text { F: } 20 \\
\text { M: } 39\end{array}$ & PCDH20 & Methylation and others & $\begin{array}{l}\text { Methylation of this PCDH } 20 \text { promoter was observed } \\
\text { in primary tumor and was associated with a shorter } \\
\text { overall survival. Moreover, the PCDH } 20 \text { methylation } \\
\text { status was an independent prognosticato }\end{array}$ \\
\hline
\end{tabular}

* Data entered for control purposes only; **, peri-lesional tissue; NI, not informed; PCDH, Protocadherin; F, female; M, male; PSA, prostatespecific antigen; BCR, biochemical recurrence; CpG, site of cytosine and guanine; AFT, Alpha Fetoprotein; TNM, Classification of Malignant Tumors.

tract and gastrointestinal tract (GIT) showed significant heterogeneity, $\mathrm{p}=0.0003$ and $\mathrm{p}=0.00001$, respectively, while the tumors of the genitourinary tract showed no heterogeneity (Figure 4).

\section{Risk of bias in individual studies}

A summary of the risk of bias of the 26 studies included in this meta-analysis has been presented in Table 2 . Three studies were classified as having a moderate risk of bias, while in other studies the risk of bias was low. The criteria for inclusion in the sample were clearly defined (Table 2) in five studies (Yu et al., 2009; Haruki et al., 2010; Lin et al., 2012; Danese et al., 2013; Lin et al., 2013). Confounding factors were uncertain, and strategies for dealing with these factors were not applied in all studies. The other items were entirely scored as "yes"

\section{Discussion}

PCDHs are proteins that play an important role in establishing specific cell connections and developing tumors (Narayan et al., 2009; Harada et al., 2015; Keeler et al., 2015; Shi et al., 2015; Deng et al., 2016; Lee et al., 2016; Ye et al., 2017). Ours is the first systematic review and meta-analysis, in which we investigated the $\mathrm{PCDH}$ activity in carcinogenesis, in the available literature. Seven types of PCDHs were analyzed: $P C D H 7$, PCDH8, PCDH9, PCDH10, PCDH17, PCDH20, and u-PCDH. PCDH10, PCDH17, and PCDH8 were the most researched and were located at the chromosomal loci 4q28.3, 13q14.3, and 4p15, respectively.

$\mathrm{PCDH} 10$ is a non-fragmented delta2-PCDH (subgroup of the delta-PCDH subfamily), with a unique cytoplasmic domain (Hirano et al., 1999); and unlike other members of the $P C D H$ family, $P C D H 10$ was found to exhibit widespread expression (Wolverton and Lalande, 2001). 


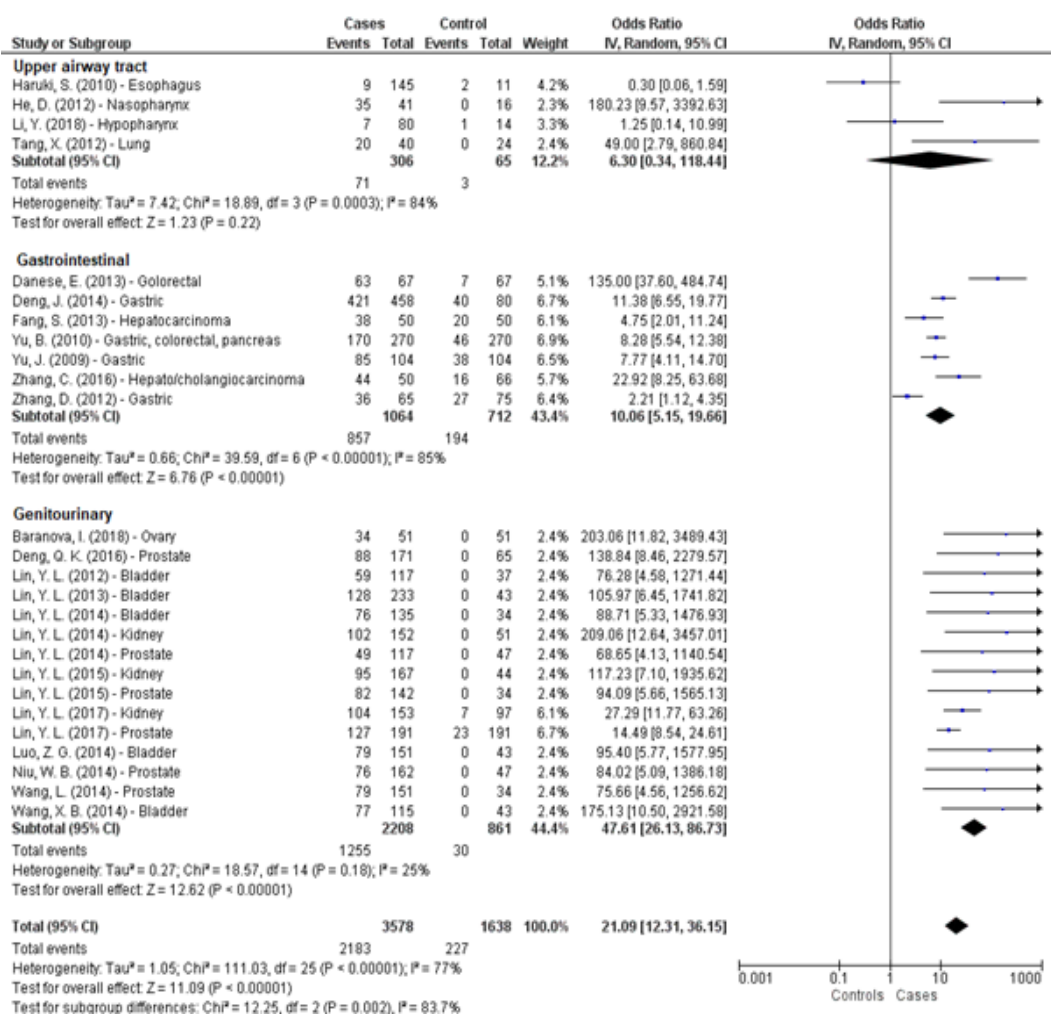

Figure 4. Methylation Profile in Human Malignant Neoplasms $(\mathrm{n}=26)$ Categorized by Group

Table 2. Summary of Risk Assessment of Bias in Individual Studies $(\mathrm{n}=26)$.

\begin{tabular}{lc}
\hline Author (year), Country & $\begin{array}{c}\text { Risk of bias in } \\
\text { individual studies }\end{array}$ \\
\hline Baranova et al. (2018), Czech Republic & Low \\
Li et al. (2018), China & Low \\
Lin et al. (2017), China & Low \\
Lin et al. (2017), China & Low \\
Zhang et al. (2016), China & Moderate \\
Deng et al.(2016), China & Low \\
Lin et al. (2015), China & Low \\
Lin et al. (2015), China & Low \\
Deng et al. (2014), China & Low \\
Lin et al. (2014), China & Low \\
Lin et al. (2014), China & Low \\
Lin et al. (2014), China & Low \\
Luo et al. (2014), China & Low \\
Niu et al. (2014), China & Low \\
Wang et al. (2014), China & Moderate \\
Wang et al. (2014), China & Low \\
Danese et al. (2013), Italy & Low \\
Fang (2013), China & Low \\
Hin (2013), China & Low \\
Hin et al. (201 & Low \\
\hline
\end{tabular}

PCDH8 and PCDH17, in contrast, may have multiple tumor suppression functions, such as involvement in cell-cell adhesion, signal transduction, and growth control, although the exact function of both the PCDHs is poorly understood. $P C D H s$ are often inactivated by DNA methylation in different neoplasms and function as tumor suppressors. In addition, it was observed that the immunoreactivity of $P C D H s$ was downregulated in specimens (Ma et al., 2013; Zhang et al., 2016; Cao et al., 2018; Li et al., 2018); and protein expression was re-duced in methylated tumors, in comparison to non-cancerous tissues or tissues in which there was no methylation (Harada et al., 2015).

Lung cancer accounts for $13 \%$ of new cancer cases and is the leading cause of cancer mortality, representing the highest age-standardized mortality rate (26.6 deaths per 100,000 popula-tion) (GBD 2015 Mortality and Causes of Death Collaborators, 2016). Hypopharyngeal carci-noma (HFC) is predominantly squamous cell carcinoma and is the reason for about $5 \%$ of head and neck cancers. Nasopharyngeal carcinoma (NFC) is a highly malignant disease, which is more prevalent in southern China, with the overall survival period being 5 years in $70 \%$ of the patients afftected (Chou et al., 2008). The evaluation of the role of $P C D H s$ in this group of neoplasms was performed and reported in seven studies $(16.3 \%)$.

$\mathrm{PCDH} 8$ functions as a tumor suppressor ( $\mathrm{Li}$ et al., 2018). PCDH8 methylation was detected in tumor tissues and not in non-tumor tissues (He et al., 2012; Li et al., 2018). PCDH8 expression was dysregulated or completely silenced in HFC tumor tissues (Li et al., 2018) and NFC cell lines (He et al., 2012), and the low expression was correlated to the advanced pathological stage of HFC.

PCDH1O hypermethylation was detected in lung 
cancer tissues; however, no association was found between the clinicopathological features, except for the smoking pattern (Tang et al., 2013). In addition, it was observed that there was no difference in recurrence pattern in patients (with or without $P C D H 10$ methylation) (Harada et al., 2015).

$P C D H 20$ expression was detected in normal lung and nasopharyngeal tissues, but was silenced or downregulated in non-small cell lung cancer and nasopharyngeal cell lines (Imoto et al., 2006; Chen et al., 2015); the same was also observed in nasopharyngeal carcinoma tissues (Chen et al., 2015). However, $P C D H 20$ methylation was not associated with the clinicopatho-logical features in NFC (Chen et al., 2015), but was associated with the clinical outcome in severe lung cancer, indicating that the inactivation of PCDH20 could occur regardless of the stage of cancer and that malignancy progression may be involved in this fact (Imoto et al., 2006). Thus, $P C D H 20$ may have several tumor suppression functions, potentially contributing to tumor growth control, signal transduction, and cell-cell adhesion (Chen et al., 2015).

From this meta-analysis, we observed that the combined odds ratio in upper airway tract tumors of 6.3 (95\% CI $=0.34-118.44)$ for $P C D H$ methylation and that these proteins could be biomarkers for early detection of tumors. However, the evidence is not strong because of the heterogeneity in results. Thus, further studies are needed to confirm the effectiveness of using $P C D H$ as a biomarker of the tumors discussed herein.

Digestive tract tumors represent a large fraction of human cancers and can occur anywhere in the gastrointestinal tract, but the most common sites are the colon and the rectum. The role of $P C D H s$ in this group of neoplasms has been evaluated in fifteen studies, and the most re-searched are $P C D H 7, P C D H 8, P C D H 9$, and PCH10.

Genetic deletion is pivotal for $\mathrm{PCDH} 10$ inactivation in colorectal cancer (CRC), and PCDH10 silencing or downregulation occurs more frequently in tumor cell lines and primary tumors compared to normal mucosa (Jao et al., 2014). Allelic loss of $P C D H 10$ is also associated with the progression of clinical staging and distant metastasis. Additionally, this type of loss is an independent prognostic factor for predicting poor survival in patients with CRC. Thus, $P C D H$ acts as a tumor suppressor in CRC and plays a role in the restriction of liver metastasis (Jao et al., 2014); PCDH10 methylation can be detected in patient's blood circulation (Danese et al., 2013).

The immunoexpression of $\mathrm{u}-\mathrm{PCDH}$ is silenced in CRC and its downregulation occurs in both tumor samples and cell lines (Losi et al., 2010). $u-P C D H$ has also been shown to retain $\beta$-catenin in the cell membrane of normal colon enterocytes, which implies that the release of $\beta$-catenin from this site and translocation to the nucleus in tumor cells has occurred (Losi et al., 2010).

Reduced PCDH17 expression was observed in esophageal squamous cell carcinoma and was closely linked to hypermethylation in the $\mathrm{CpG}$-rich region (Haruki et al., 2010). However, other mechanisms, including posttranslational modification, may contribute to this reduction (Haruki et al., 2010). Poorly differentiated tumors are negative for $P C D H 17$. In addition, in non-neoplastic esophageal epithelia, $\mathrm{PCDH} 17$ was expressed in the spinous cell layers, implying that this fact may be dependent on the status of cell differentiation and that the silenced expression acts on the de-differentiation of esophageal neoplasms (Haruki et al., 2010).

Gastric cancer (GC) is the fourth most common gastrointestinal tumor and presents a high mortality rate (Isomoto et al., 2008). In this cancer, $P C D H 7$ immunoexpression showed a gradual reduction in the normal tissue to intraepithelial neoplasia and GC, and an even lower immunoexpression in CG lymph node metastasis (Chen et al., 2017). This immunoexpression was inversely or negatively correlated with Lauren's classification, lymph node metastases, and TNM stage (Chen et al., 2017). This demonstrates that PCDH7 suppresses GC progression (Chen et al., 2017).

It has also been observed that the loss of expression and high methylation of the $\mathrm{PCDH} 8$ promoter have been detected in the tumor cells of GC. PCDH8 methylation was also found in peri-lesional tissues, but not in normal gastric tissue, and was associated with lymph node metastasis (Zhang et al., 2012). Loss of PCDH9 expression is associated with epithelial dif-ferentiation and cell metastasis in gastric cancer (Chen et al., 2015).

There is a significant correlation between methylation and loss of PCDH10 expression in GC (Yu et al., 2010), and it is silenced or downregulated in GC cell lines. This is the major regulatory mechanism of $\mathrm{PCDH} 10$ inactivation (Yu et al., 2009; Deng et al., 2014). However, there was no association between staging and methylation, which may occur because $\mathrm{PCDH} 10$ methylation is supposed to be the cause rather than the result of carcinogenesis. This suggests that PCDH1O methylation can be used as a marker for early stage cancer diagnosis (Yu et al., 2010), and the counting of methylated $\mathrm{CpG}$ islands has clinical prognostic assessment applicability (Deng et al., 2014; Hou et al., 2015).

Liver cancer is the sixth most commonly diagnosed cancer, the fourth leading cause of cancer death worldwide in 2018, and is most prevalent cancer in Africa and Asia (Bray et al., 2018). PCDH10, PCDH17 and PCDH2O expression levels were downregulated in this neoplasm.

Low PCDH10 expression correlates with tumor size, TNM stage, smoking status, and alcohol consumption pattern (Bing et al., 2019). The ectopic expression of PCDH10, when silenced by methylation, can suppress tumor cell growth, migration, invasion, and colony formation (Fang et al., 2013). In addition, PCDH2O can inhibit metastasis by preventing cell migration (Lv et al. 2015), because it is a sensitive clinical parameter to predict survival in indolent and early stage cases (Wu et al., 2017).

The $P C D H 17$ knockout can inhibit the proliferation, migration, and invasion of hepatocarci-noma cells through the overactivation of the EGFR/MEK/ERK signaling pathway (Dang et al., 2016). PCDH8 methylation correlates with alpha-fetoprotein (AFP) levels in patients with AFP levels $>50 \mathrm{ng} / \mathrm{mL}$ (Zhang et al., 2016). Thus, methylation is the main mechanism of loss of expression in hepatocarcinoma (Zhang et al., 2016).

Thus, we observed from the studies significant Asian Pacific Journal of Cancer Prevention, Vol 213685 
heterogeneity $(p<0.001)$, the value of odds of association between methylation and cancer being 10.06 (95\% CI = 5.15-19.66). Thus, PCDHs could be biomarkers for the early detection of GIT cancers. However, the evidence is not strong because to the results, for the reason that the results were not sufficiently homogeneous. This fact can be explained by the heterogeneity of the lesions that involve this group of neoplasms with different etiopathogenesis.

Bladder cancer (BC) is a heterogeneous disease, the outcome of which is difficult to predict, and ranks 10th in cancer incidence worldwide (Kaufman et al., 2009; Grossman, 2011; Mossanen and Gore, 2014). BC can be classified into two types, that is, noninvasive muscle $\mathrm{BC}$ (NIMBC) and invasive muscle BC (IMBC), based on histopathological and clinical aspects (Sun and Trinh, 2015). In many studies, the role of PCDHs in this type of cancer has been evaluated, and the immunohistochemical and methylation profiles were the adopted methodologies. The immunoreactivity levels of $\mathrm{PCDH7}$ and $\mathrm{PCDH} 10$ proteins are lower in NIMBC tissues than in normal bladder epithelial tissues (Ma et al., 2013; Lin et al., 2016). Low PCDH7 immunoexpression has been associated with high pathological grade, recurrence, and tumor progression; this fact is an independent prognostic factor for clinical outcome (Lin et al., 2016) and is associated with BC invasiveness (Ma et al., 2013).

Prostate cancer (PC) is the fifth leading cause of death in men and is a molecularly heterogeneous disease. Therefore, there is no accurate predictive marker for outcome assessment in cancer patients (Jao et al., 2014). Methylation could occur in $\mathrm{PCDH8}, \mathrm{PCDH10}$, and PCDH17 in both PC tumor tissue and serum, and is associated with poor prognosis and shorter biochemical relapse-free survival (Losi et al., 2011; Lin et al., 2014; Viu et al., 2014; Wang et al., 2014; Lin et al., 2015; Lin et al., 2017).

Ovarian cancer (OC) is the second most lethal cancer among women worldwide (Siegel et al., 2017), and PCDHs may represent as a possible direction in the search for tumor biomarkers. $\mathrm{PCDH} 17$ methylation is important in OC carcinogenesis (Baranova et al., 2018). In addition, low $\mathrm{PCDH8}$ immunoexpression in $\mathrm{OC}$ tissues predicts a poor prognosis (Cao et al., 2018).

Renal carcinoma ( $\mathrm{RC}$ ) is one of the most commonly diagnosed urinary malignancies, and the most common histological subtype is clear cell RC, accounting for $80 \%$ to $90 \%$ of cases (Low et al., 2016; Capitanio and Montorsi, 2016). Aberrant methylation of tumor suppressor genes is involved in tumor initiation and progression (Shenoy et al., 2015). The frequency of PCDH8 and PCDH17 methylation is high in this cancer, and the PCDHs are associated with malignancy clinicopathological characteristics and unfavorable prognosis (Lin et al., 2014; Lin et al., 2015).

In this meta-analysis, we have shown strong evidence for the occurrence of methylation of some PCDHs in the group of neoplasms discussed in this article, and this is because the results were sufficiently homogeneous. Thus, methylation is a specific event for the tumors discussed and can occur in $\mathrm{PCDH7}$ PCDH8, PCDH10, and $P C D H 17$.
Most of the studies had the subjects and configuration described in detail, reliably measured the results, and used statistical analysis. On the other hand, we did not identify confounding factors, nor did they describe strategies to minimize these factors.

This review has certain limitations that must be taken into consideration. None of the articles reported the sample size calculation; all census-type samples were collected for convenience. Age was reported heterogeneously in the studies, and it was not possible to categorize individuals to verify the most affected age group. There was a heterogeneous geographic distribu-tion of studies, focusing on Asia. In this review, the research was limited to clinical samples and laboratory techniques, and it was not possible to speculate the definitive clinical utility of PCDHs. In addition, there was no standardization of the methodologies adopted. In most of the studies, no follow-up of patients with regard to recurrence and disease progression was reported. Finally, the heterogeneity of malignancies and $\mathrm{PCDHs}$ made it difficult for us to compare the large number of studies included.

In this systematic review, we have demonstrated that $\mathrm{PCDHs}$ are often silenced by DNA methylation in different malignant neoplasms, of which genitourinary tract tumors are more prevalent. Thus, $P C D H s$ could emerge as potential tumor suppressor genes, and a significant increase in methylation may be useful for early detection of different types of cancers. Moreover, the existence of methodologies with great heterogeneity reinforces the importance of studies to evaluate the role of this group of proteins in the carcinogenesis of other neoplasms.

\section{Acknowledgements}

Ethical approval and consent to participate Not applicable.

\section{Funding}

This work was supported by grants from Fundação Cearense de Apoio ao Desenvolvimento Científico e Tecnológico (FUNCAP)/Brazil and Coordenação de Aperfeiçoamento de Pessoal de Nível Superior (CAPES)/ Brazil.

\section{Author's Contribution}

TTBD: Conceptualization, Methodology, Investigation, Writing - Original Draft; TMMB: Investigation, Writing - Original Draft; EMCL: Investigation, Writ-ing Original Draft; FSRC: Conceptualization, Methodology, Investigation; FNC: Conceptualization, Methodology, Writing - Review and Editing; PGBS: Conceptualization, Methodology, Formal analysis; FWGC: Conceptualization, Methodology, Writing - Review and Editing; KMAP: Conceptualization, Methodology, Writing - Review and Editing, Supervision.

\section{Conflict of interest}

The authors have no existing conflict of interest. 


\section{References}

Baranova I, Kovarikova H, Laco J, et al (2018). Aberrant methylation of PCDH17 gene in high-grade serous ovarian carcinoma. Cancer Biomark, 23, 125-33.

Beukers W, Hercegovac A, Vermeij M, et al (2013). Hypermethylation of the polycomb group target gene PCDH7 in bladder tumors from patients of all ages. $J$ Urol, 190, 311-6.

Bing Y, Tian M, Li G,Gang Li, et al (2019). Down-regulated of PCDH10 predicts poor prog-nosis in hepatocellular carcinoma patients. Medicine (Baltimore), 97, e12055.

Bray F, Ferlay J, Soerjomataram I, et al (2018). Global cancer statistics 2018: GLOBOCAN estimates of incidence and mortality worldwide for 36 cancers in 185 countries. $C A$ Cancer J Clin, 68, 394-424.

Cao Y, Yu Y, Chen X, et al (2018). Low expression of protocadherin- 8 promotes the pro-gression of ovarian cancer. Int J Gynecol Cancer, 28, 346-54.

Capitanio U, Montorsi F (2016). Renal cancer. Lancet, 387, 894-906.

Chen HF, Ma RR, He JY, et al (2017) Protocadherin 7 inhibits cell migration and invasion through E-cadherin in gastric cancer. Tumour Biol, 39.

Chen T, Long B, Ren G, et al (2015). Protocadherin20 acts as a tumor suppressor gene: Epigenetic Inactivation in Nasopharyngeal Carcinoma. J Cell Biochem, 116, 1766-75.

Chen Y, Xiang H, Zhang Y, Wang J, Yu G (2015). Loss of PCDH9 is associated with the differentiation of tumor cells and metastasis and predicts poor survival in gastric cancer. Clin Exp Metastasis, 32, 417-28.

Chou J, Lin YC, Kim J, et al (2008) Nasopharyngeal carcinomareview of the molecular mechanisms of tumorigenesis. Head Neck, 30, 956-63.

Danese E, Minicozzi AM, Benati M, et al (2013). Epigenetic alteration: new insights moving from tissue to plasma - the example of PCDH10 promoter methylation in colorectal cancer. Br J Cancer, 109, 807-13.

Dang Z, Shangguan J, Zhang C, et al (2016). Loss of protocadherin-17 (PCDH-17) promotes metastasis and invasion through hyperactivation of EGFR/MEK/ERK signaling pathway in hepatocellular carcinoma. Tumour Biol, 37, 2527-35.

Deng J, Liang H, Ying G, et al (2014). Clinical significance of the methylated cytosine-phosphate-guanine sites of protocadherin-10 promoter for evaluating the prognosis of gastric cancer. J Am Coll Surg, 219, 904-13.

Deng QK, Lei YG, Lin YL, Ma JG, Li WP (2016). Prognostic value of protocadherin10 (PCDH10) methylation in serum of prostate cancer patients. Med Sci Monit, 22, 516-21.

Fang S, Huang SF, Cao J, et al (2012). Silencing of PCDH10 in hepatocellular carcinoma via de novo DNA methylation independent of HBV infection or HBX expression. Clin Exp Med, 13, 127-34.

GBD 2015 Mortality and Causes of Death Collaborators (2016). Global, regional, and nation-al life expectancy, all-cause mortality, and cause-specific mortality for 249 causes of death, 1980-2015: a systematic analysis for the Global Burden of Disease Study 2015. Lancet, 388, 1459-544.

Grossman HB (2011). Bladder cancer: neoadjuvant is new again. Lancet Oncol, 12, 830-1.

Harada H, Miyamoto K, Yamashita Y, et al (2015). Prognostic signature of protocadherin 10 methylation in curatively resected pathological stage I non-small-cell lung cancer. Cancer Med, 4, 1536-46.

Haruki S, Imoto I, Kozaki K, et al (2010). Frequent silencing of protocadherin 17, a candidate tumour suppressor for esophageal squamous cell carcinoma. Carcinogenesis, 31, 1027-36.

He D, Zeng Q, Ren G, et al (2012). Protocadherin8 is a functional tumor suppressor frequent-ly inactivated by promoter methylation in nasopharyngeal carcinoma. Eur $J$ Cancer Prev, 21, 569-75.

Hirano S, Yan Q, Suzuki ST (1999). Expression of a novel protocadherin, OL-protocadherin, in a subset of functional systems of the developing mouse brain. $J$ Neurosci, 19, 995-1005

Hou YC, Deng JY, Zhang RP, et al (2015). Evaluating the clinical feasibility: The direct bi-sulfite genomic sequencing for examination of methylated status of protocadherin 10 (PCDH10) promoter to predict the prognosis of gastric cancer. Cancer Biomark, 15, 567-73.

$\mathrm{Hu}$ X, Sui X, Li L, et al (2013). Protocadherin 17 acts as a tumour suppressor inducing tumour cell apoptosis and autophagy, and is frequently methylated in gastric and colorectal cancers. J Pathol, n.229, n.1, 62-73, 2013. J Pathol, 229, 62-73.

Imoto I, Izumi H, Yokoi S, et al (2006). Frequent silencing of the candidate tumor suppres-sor PCDH20 by epigenetic mechanism in non-small-cell lung cancers. Cancer Res, 66, 4617-26.

Isomoto H, Shikuwa S, Yamaguchi N, et al (2009). Endoscopic submucosal dissection for early gastric cancer: a large-scale feasibility study. Gut, 58, 331-6.

Jao TM, Tsai MH, Lio HY, et al (2014). Protocadherin 10 suppresses tumorigenesis and me-tastasis in colorectal cancer and its genetic loss predicts adverse prognosis. Int $J$ Cancer, 135, 2593-603.

Kaufman DS, Shipley WU, Feldman AS (2009). Bladder cancer. Lancet, 374, 239-49.

Keeler AB, Molumby MJ, Weiner JA (2015). Protocadherins branch out: Multiple roles in dendrite development. Cell Adh Migr, 9, 214-26.

Kim SY, Yasuda S, Tanaka H, Yamagata K, Kim H (2011). Non-clustered protocadherin. Cell Adh Migr, 5, 97-105.

Lee NK, Lee JH, Kim WK, et al (2016). Promoter methylation of PCDH10 by HOTAIR regulates the progression of gastrointestinal stromal tumors. Oncotarget, 7, 75307-18.

Li Y, Liu C, Wang Z, Hu G (2018). Expression of protocadherin8: Function as a tumor sup-pressor in hypopharyngeal carcinoma. Cancer Biomark, 22, 495-502.

Lin YL, Li ZG, He ZK, Guan TY, Ma JG (2012). Clinical and prognostic significance of pro-tocadherin-10 (PCDH10) promoter methylation in bladder cancer. J Int Med Res, 40, 2117-23.

Lin YL, Ma JH, Luo XL, Guan TY, Li ZG (2013). Clinical significance of protocadherin-8 (PCDH8) promoter methylation in bladder cancer. $J$ Int Med Res, 41, 48-54.

Lin YL, Wang YL, Fu XL, Ma JG (2014). Aberrant methylation of PCDH8 is a potential prognostic biomarker for patients with clear cell renal cell carcinoma. Med Sci Monit, 20, 2380-5.

Lin YL, Wang YL, Ma JG, Li WP (2014). Clinical significance of protocadherin 8 (PCDH8) promoter methylation in nonmuscle invasive bladder cancer. J Exp Clin Cancer Res, 33, 68 .

Lin YL, Xie PG, Wang L, Ma JG (2014). Aberrant methylation of protocadherin 17 and its clinical significance in patients with prostate cancer after radical prostatectomy. Med Sci Monit, 20, 1376-82.

Lin YL, Deng QK, Wang YH, et al (2015). Aberrant protocadherin 17 (PCDH17) methylation in serum is a potential predictor for recurrence of early-stage prostate cancer patients after radical prostatectomy. Med Sci Monit, 
21, 3955-690.

Lin YL, Gui SL, Guo H, Ma JG, Li WP (2015). Protocadherin 17 promoter methylation is a potential predictive biomarker in clear cell renal cell carcinoma. Med Sci Monit, 21, 2870-6.

Lin YL, Wang YL,Fu XL, et al (2016). Low expression of protocadherin7 ( $\mathrm{PCDH} 7)$ is a po-tential prognostic biomarker for primary non-muscle invasive bladder cancer. Oncotarget, 7, 28384-92.

Lin YL, Li YL, Ma JG (2017). Aberrant promoter methylation of protocadherin8 (PCDH8) in serum is a potential prognostic marker for low gleason score prostate cancer. Med Sci Monit, 23, 4895-4900.

Lin YL, Wang YP, Li HZ, Zhang X (2017). Aberrant promoter methylation of PCDH17 (Protocadherin 17) in serum and its clinical significance in renal cell carcinoma. Med Sci Monit, 23, 3318-23.

Losi L, Parenti S, Ferrarini F, et al (2011). Down-regulation of $\mu$-protocadherin expression is a common event in colorectal carcinogenesis. Hum Pathol, 42, 960-71.

Low G, Huang G, Fu W, Moloo Z, Girgis S (2016). Review of renal cell carcinoma and its com- mon subtypes in radiology. World J Radiol, 8, 484-500.

Luo ZG, Li ZG, Gui SL, Chi BJ, Ma JG (2014). Protocadherin-17 promoter methylation in serum-derived DNA is associated with poor prognosis of bladder cancer. $J$ Int Med Res, 42, 35-41.

Lv J, Zhu P, Yang Z, et al (2015). PCDH20 functions as a tumour-suppressor gene through antagonizing the Wnt/ beta-catenin signalling pathway in hepatocellular carcinoma. $J$ Viral Hepat, 22, 201-11.

Ma JG, He ZK, Ma JH, Li WP, Sun G (2013). Downregulation of protocadherin-10 expres-sion correlates with malignant behaviour and poor prognosis in human bladder cancer. J Int Med Res, 41, 38-47.

Mossanen M, Gore JL (2014). The burden of bladder cancer care: direct and indirect costs. Curr Opin Urol, 24, 487-91.

Narayan G, Scotto L, Neelakantan V, et al (2009). Protocadherin PCDH10, involved in tumor progression, is a frequent and early target of promoter hypermethylation in cervical cancer. Genes Chromosomes Cancer, 48, 983-92.

Niu WB, Gui SL, Lin YL, et al (2014). Promoter methylation of protocadherin8 is an Inde-pendent prognostic factor for biochemical recurrence of early-stage prostate cancer. Med Sci Monit, 20, 2584-9.

Shenoy N, Vallumsetla N, Zou Y, et al (2015). Role of DNA methylation in renal cell carci-noma. J Hematol Oncol, 8, 88.

Shi D, Murty VV, Gu W (2015). PCDH10, a novel p53 transcriptional target in regulating cell migration. Cell Cycle, 14, 857-66.

Siegel RL, Miller KD, Jemal A, et al (2017). Cancer statistics, 2017. CA Cancer J Clin, 67, 177-93.

Sun M, Trinh QD (2015). Diagnosis and staging of bladder cancer. Hematol Oncol Clin North Am, 29, 205-18.

Tang X, Yin X, Xiang T, et al (2013). Protocadherin 10 is frequently downregulated by pro-moter methylation and functions as a tumor suppressor gene in non-small cell lung cancer. Cancer Biomark, 12, 11-9.

Wang L, Xie PG, Lin YL, Ma JG, Li, WP (2014). Aberrant methylation of PCDH10 predicts worse biochemical recurrence-free survival in patients with prostate cancer after radical prostatectomy. Med Sci Monit, 20, 1363-8.

Wang XB, Lin YL, Li ZG, et al (2014). Protocadherin 17 promoter methylation in tumour tissue from patients with bladder transitional cell carcinoma. J Int Med Res, 42, 292-9.

Wolverton T, Lalande M (2001). Identification and characterization of three members of a novel subclass of protocadherins. Genomics, 76, 66-72.
Wu Y, Zheng S, Yao J, et al (2017). Decreased expression of protocadherin 20 is associated with poor prognosis in hepatocellular carcinoma. Oncotarget, 8, 3018-28.

Yagi T, Takeichi M (2000). Cadherin superfamily genes: functions, genomic organization, and neurologic diversity. Genes Dev, 14, 1169-80.

Ye M, Li J, Gong J (2017). PCDH10 gene inhibits cell proliferation and induces cell apoptosis by inhibiting the PI3K/Akt signaling pathway in hepatocellular carcinoma cells. Oncol Rep, 37, 3167-74.

Yu J, Cheng YY, Tao Q, et al (2009). Methylation of protocadherin 10, a novel tumor sup-pressor, is associated with poor prognosis in patients with gastric cancer. Gastroenterology, 136, 640-51.

Yu B, Yang H, Zhang C, et al (2010). High-resolution melting analysis of PCDH10 methyla-tion levels in gastric, colorectal and pancreatic cancers. Neoplasma, 57, 247-52.

Zhang D, Zhao W, Liao X, et al (2012). Frequent silencing of protocadherin 8 by promoter methylation, a candidate tumor suppressor for human gastric cancer. Oncol Rep, 28, 1785-91.

Zhang C, Peng Y, Yang F, et al (2016). PCDH8 is frequently inactivated by promoter hy-permethylation in liver cancer: Diagnostic and Clinical Significance. J Cancer, 7, 446-52.

Zhong X, Shen H, Mao J, Zhang J, Han W (2017). Epigenetic silencing of protocadherin 10 in colorectal cancer (Review). Oncol Lett, 13, 2449-53

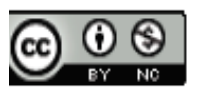

This work is licensed under a Creative Commons AttributionNon Commercial 4.0 International License. 